\title{
Using Technology To Increase Critical-Thinking In Undergraduate Business Study
}

David L. Sturges, (Email: dsturges@utpa.edu), University of Texas, Pan American Teo Ozuna, (Email: ozuna@utpa.edu),University of Texas, Pan American

\begin{abstract}
This paper describes technological application designed to focus on student-learner approaches to education to develop critical-thinking among undergraduate students. The high-tech classroom achieves the critical-thinking objective and reduces seat-time so colleges overcome ever-growing shortages of classroom space.
\end{abstract}

\section{INTRODUCTION}

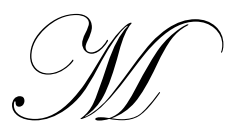

uch has been studied and written about diffusion of technology into operational environments of a myriad of settings, among them is the educational environment. Technology is seen by many to be the learning assistance tools to overcome a plethora of learning inabilities among elementary students, and to some extent secondary students. (Bowerman, 2005) Application of technology to higher education also offers options to address learning styles, but more often it is perceived by higher education administrators to be a tool to increase students access, and therefore revenues, without an attendant increase in operation cost.

In higher education, the most likely truth is a combination of these concepts. That is, technology is a tool to increase student access (Banas, 1998), but it provides the opportunity to create course content and delivery of a highly robust, enriched and, yes, entertaining format that appeals to modern student learning desires (Sturges, 2004). For a student target base weaned on television cartoons and coming of age to MTV, attention spans, interest-focusing content, and quality of production are essential elements to a successful educational experience by attracting and retaining students to build a competency level of topic understanding to achieve a knowledge base similar to or exceeding traditional techniques of higher education.

\section{THE TECHUCATIONAL CHALLENGE}

Technologies applied to teaching and learning have always been present. As time has progressed the technologies have changed. A few decades ago, these technologies consisted of such classroom enhancements as chalkboards, overhead projectors, and classroom visits by outside speakers. Today, the concept of technology in the classroom is associated with the application of computers, computer-aided learning techniques, and increasingly sophisticated learning software and how they can replace or substitute previous technologies in learning processes.

The expansion of computer-related technologies into class environments has resulted in a myriad of possible applications. IT functions at many institutions have attempted to incorporate technology options into classrooms. These installations typically have several technologies, including computers for presentation display, Internet connection, VCRs, document cameras, DVD players, and audio systems. What is missing is faculty adoption of the technologies and the attendant effort to overcome the learning curve to effectively and efficiently incorporate the technology options into classroom content. Instead, most applications are applied to the educational process singularly. A faculty member might decide to incorporate visual support to lectures and will adopt presentation applications such as PowerPoint ${ }^{\mathrm{TM}}$ or Keynote ${ }^{\mathrm{TM}}$. Or, video using VHS or DVD recordings is used to provide 
entertaining illustrations to course concepts. Some adopt Internet resources to post course support materials, assignments, or discussion boards for students. Rarely do faculty take the time or effort to develop skills in using all of the available technologies to produce more robust, entertaining, interactive, and learner-centered course content to maximize the educational experience for all types of student learners.

The challenge, therefore, is to foster a more widespread and robust commitment by faculty to optimize sets of technology applications into a well-structured, accomplished, and, yes, entertaining course content targeted to delivery of specialized topics to student populations with varying learning styles. Meeting this challenge results in applications that transcend what may be considered innovative technology use today. It results in a new category that we will call "techucation." This paper will focus on one area of education concern that may be addressable by techucation.

\section{CRITICAL-THINKING IN EDUCATIONAL CONTENT}

Critical-Thinking has been the Holy Grail of education, particularly among colleges and universities, over the past two decades. In many instances of application, technology has not contributed significantly to the fostering or enhancing of critical-thinking in physical sections of classes. Instead, technology has been a method to turn class lectures into "edutainment" in an attempt to attract student attention and interest student in course content. The result is use of such technologies as PowerPoint ${ }^{\mathrm{TM}}$ slides or video recordings to enhance the entertainment level of course material. But the question arises whether incorporation of these technologies contributes to critical-thinking among students in the class. An argument can be made that it doesn't (van Gelder, 2001). So, something is missing from the equation to make these technologies' applications into the critical-thinking drivers among undergraduate students.

\section{TECHNICAL APPLICATION FOR CRITICAL-THINKING (TACT)}

Techucation for critical-thinking requires a system of technological application specifically designed to focus on student-learner approaches to education as a key to developing critical-thinking among undergraduate students.

The system, named Technology Application for Critical-Thinking (TACT), brings a myriad of technologies into a collaborative effort to foster and enhance critical-thinking in students while remaining an attractive, selfmotivating, learner-centered educational technique. The system comprises the following components:

\begin{tabular}{|l|l|l|}
\hline Technology & Application & Objective \\
\hline Online Streaming Video & Course lectures & $\begin{array}{l}\text { To fulfill students' desires for face-to- } \\
\text { face interaction and lectures from } \\
\text { recognized expert sources. } \\
\text { To reduce "seat time" for classes. }\end{array}$ \\
\hline Online Discussion Boards & $\begin{array}{l}\text { Sharing with classmates to develop } \\
\text { ideas and applications of course } \\
\text { content }\end{array}$ & $\begin{array}{l}\text { To foster a sense of collaboration and } \\
\text { cooperation among students leading to } \\
\text { team development of concept } \\
\text { understanding. }\end{array}$ \\
\hline Electronic Classroom Activity Processors & $\begin{array}{l}\text { Electronic Attendance recording and } \\
\text { module quizzing }\end{array}$ & $\begin{array}{l}\text { To rapidly identify student deficiencies } \\
\text { in study to focus on specific topics }\end{array}$ \\
\hline Electronic Presentations & $\begin{array}{l}\text { Create interesting and entertaining } \\
\text { visual support for class discussions }\end{array}$ & $\begin{array}{l}\text { To provide edutainment to attract } \\
\text { student interest and understanding in } \\
\text { class discussions. }\end{array}$ \\
\hline
\end{tabular}

Each of these technologies has been used in class content. Some courses employ more than one of these technologies. But the key to the successful improvement of learning using these tools is to ensure that they are collaborative, cooperative, extending, and entertaining through visual appearance and interactivity. This is especially important to the goal of developing critical-thinking skills in students. 


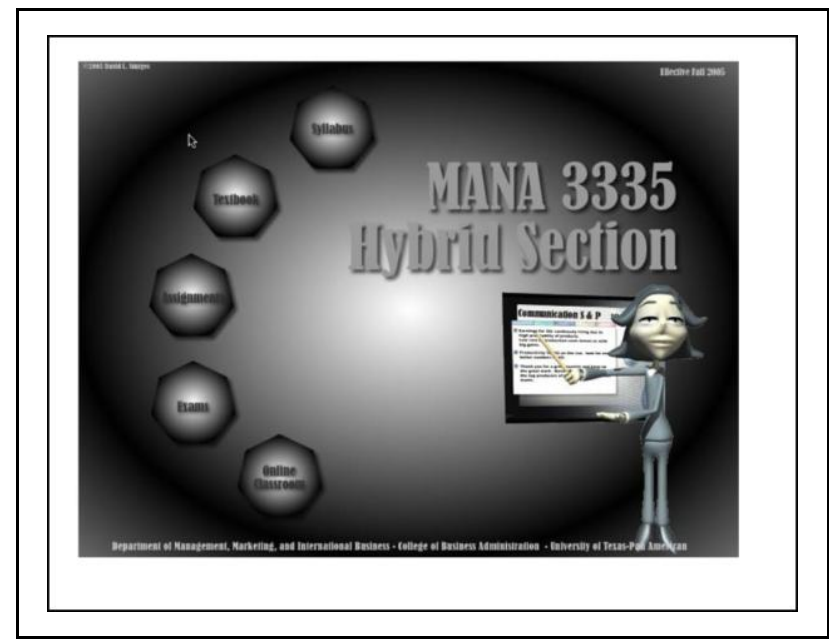

The page design includes interactivity, an important part of the goal to make the site's entry more attractive to students. As students navigate around the page, moving the cursor across various page components results in immediate changes in a somewhat video-game like appearance.

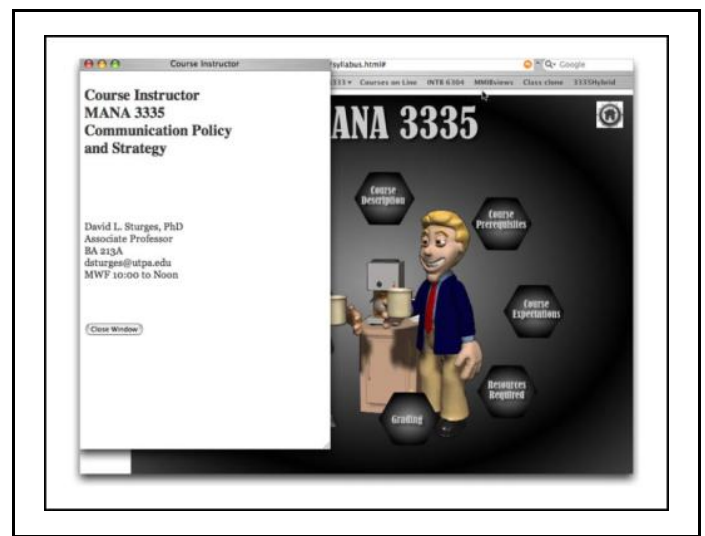

attraction feature to engage the student into the active response to the experience. The student must engage in decision-making to determine which of the interactive options to select for desired information.

Again, as the cursor is moved around the page, the floating bubbles are designed to animate to improve interest. Selecting one of the options opens a subsidiary page with the information requested.

The requested page than can be read and, upon completion, closed. The Syllabus page is once again available as a student's decision target for desired information.
A test of TACT system is currently underway. A course with multiple sections now includes sections taught with limited techucation applications, primarily visual support, and Internet access to assignments and course information. The test section of the course incorporates the TACT system to enhance and broaden the learning experience for students.

One of the first impressions upon entering the class' website is the appearance of the page graphics (see to the left). The whimsical approach to the site's design is meant to be more inviting than the entrance to many online courses served by WebCT or Blackboard, which are primarily text-based, template-driven designs.

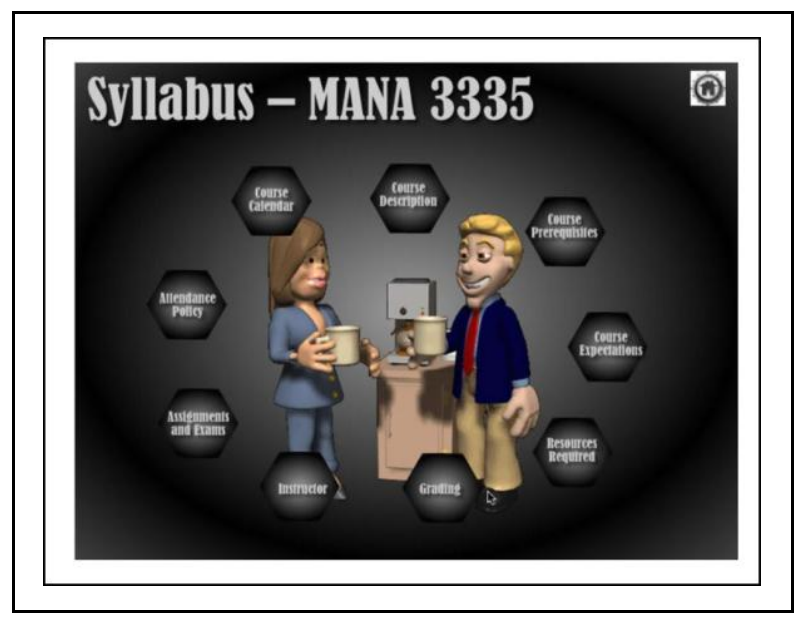

Selection of a floating bubble leads into the interactive world of the course's content. The first example is the syllabus.

Rather than a traditional text-structured syllabus, the student encounters a syllabus that induces interaction, decisionmaking, and fun. Again, the whimsical approach is used as an

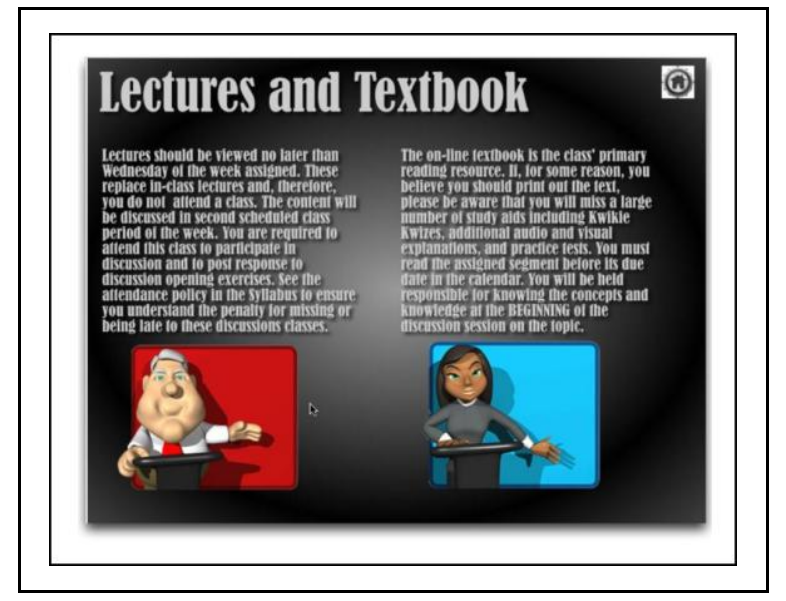




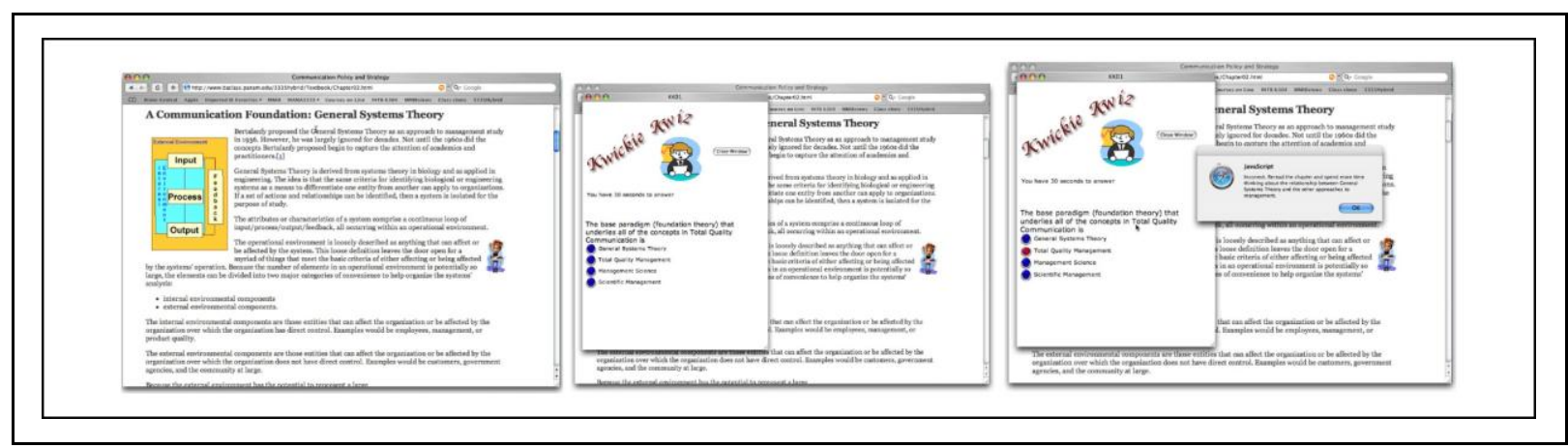

The second techucation element in the TACT system is to provide a basis for developing thinking skills while reading the online text material. Selecting the textbook bubble, accesses two options. One is the text and the other is the Lecture Hall.

Again, animated interaction adds interest. Moving the cursor across the cartoon people produces animation of the characters as well the title of the available linkage. In this case, the young woman links to the course textbook. The course textbook's entry page looks like a standard text index with links per chapter.

The online textbook has a multitude of interactive components creating a highly engaging experience filled with learning support elements that foster addition thinking by the student as they progress though a reading assignment. For example, clicking on the student cartoon character in the text opens a Kwickie Kwiz, a learning reinforcement tool. Students are immediately evaluated for comprehension of the text passage. See the illustration above.

Additional student-activated learning support includes Study Guides, subsidiary pages with audio, video, web link to associated topics, or Flash ${ }^{\mathrm{TM}}$ illustrations of concepts. The Study Helpers are designed to motivate students to applying thinking skills to the process of reading and assignment. The increased engagement potentially results in greater comprehension through the application of advanced thinking skills.

The second option on the textbook page connects to the course Lecture Hall. Accessing this resource requires students to achieve a higher level of computer literacy than is typical of students in our university's service area. Students must download video player software and install it on their computers to access the Lecture Hall videos. Of course, in our area of the country, many students do not have their own computers so this component is not consistently required across the enrolment since these students access the web site using academic computer labs. Accessing the Lecture Hall provides access for students to view streaming video of class lectures. While viewing the

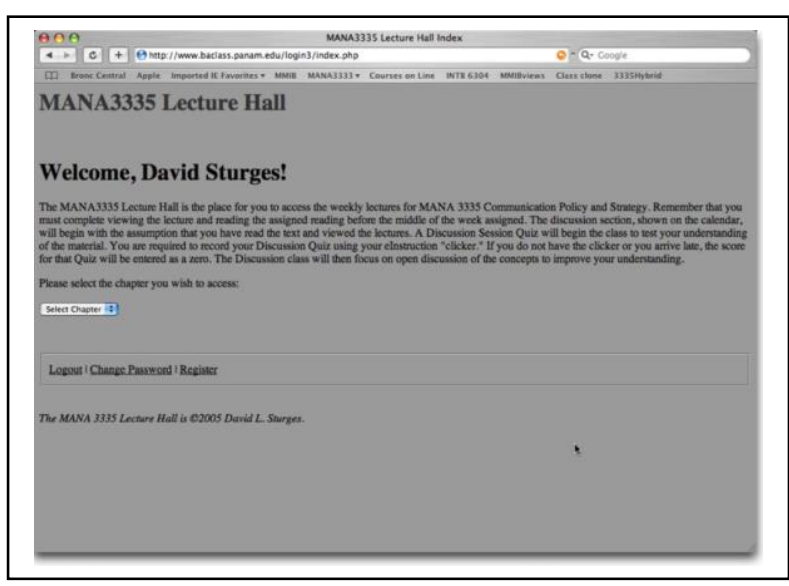
streaming lecture, student may simultaneously access the online textbook to incorporate audio/visual with the text to induce multiple learning avenues, some of which may be more significant to an individual than are others. 


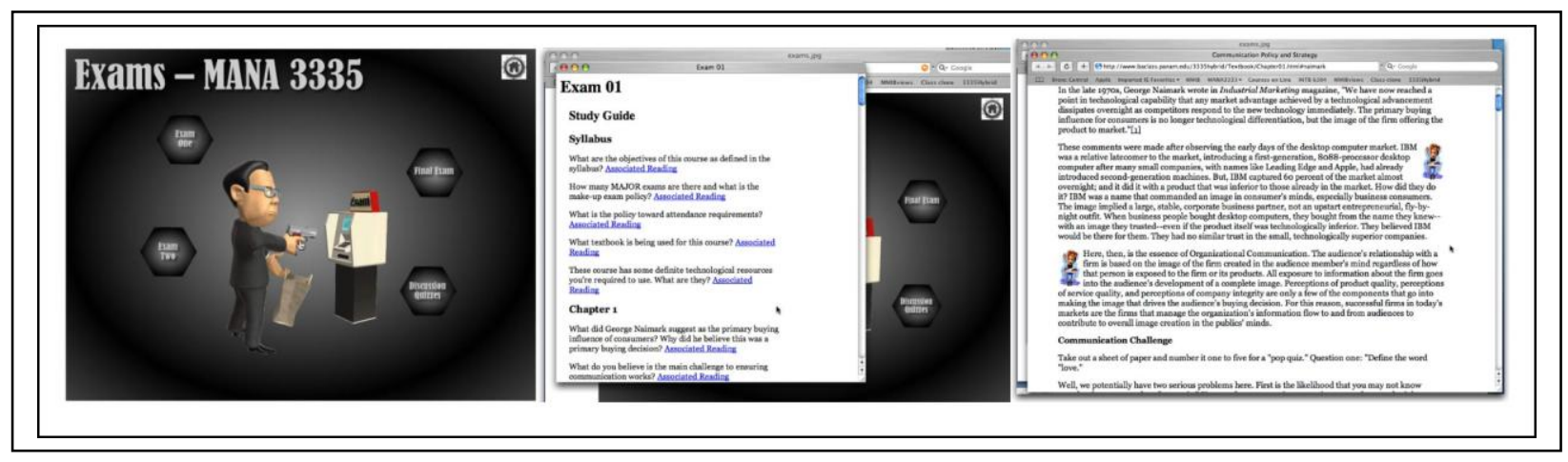

Each of the portal page bubble options has similar kinds of interaction to foster decision-making among the students for topics such as Assignments and Exams. In the case of exams, students may select a bubble associated with a targeted exams. It accesses a study page that asks questions for the students to develop answers to. Students should formulate answers based on their reading of the assignment, and its study guides, and the streaming video. Upon creation of the answer, students click on another button in the questions and are transported to the place in the online text where the topic is found. They can then compare their answer to the text. They modify their response to the text information. This process seems to produce more internalized knowledge of the topics that is comprehended more completely because the students are using multiple learning techniques and reinforcement resources to confirm understanding.

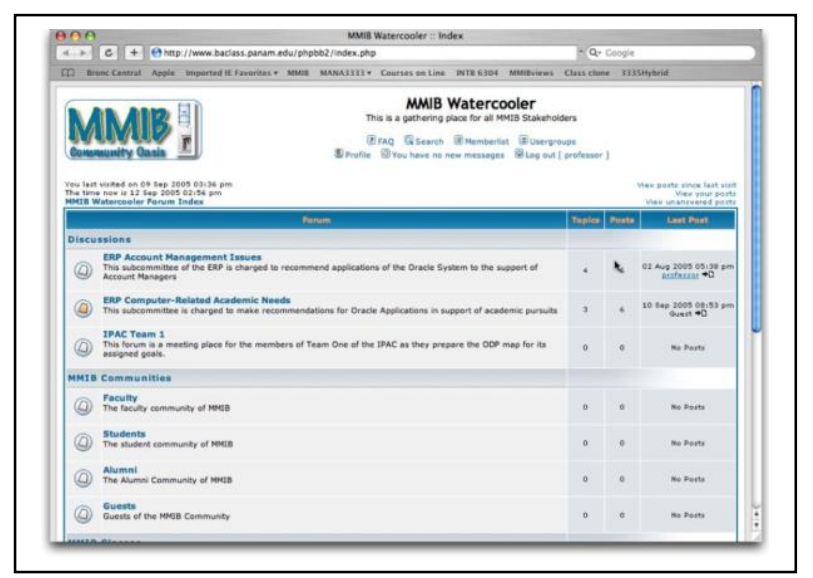

The first half of each week is the time for students to access the online resources. During this time, the students are instructed to access the class discussion board (called the Watercooler). This is an online area for students to exchange ideas, comments, and questions regarding the week's topic. They are graded for participation based on frequency and quality of postings to the Watercooler. This requires students to apply advanced thinking skills to effectively work with other students to assist them with comprehension of topics or to receive assistance from others.

class is scheduled for a physical meeting toward the end of the week. The expectation is that students will have completed all of the TACT components assigned during the week. The first activity of the discussion session is a

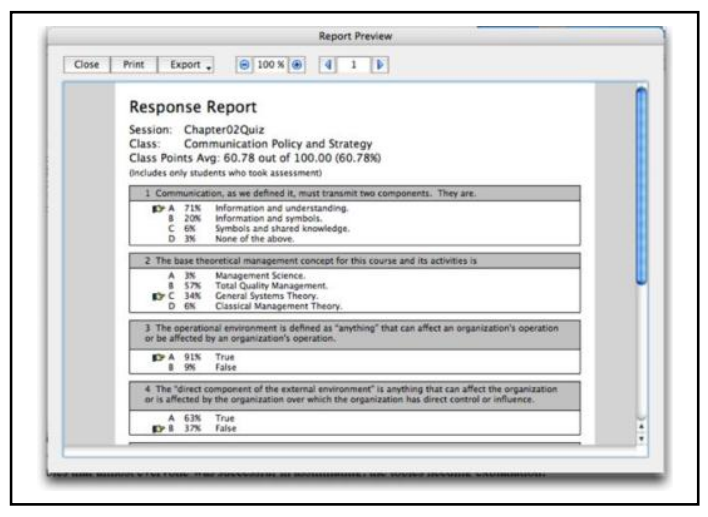
quiz that is taken using an electronic response device (see right). The student uses this device to respond to ten to

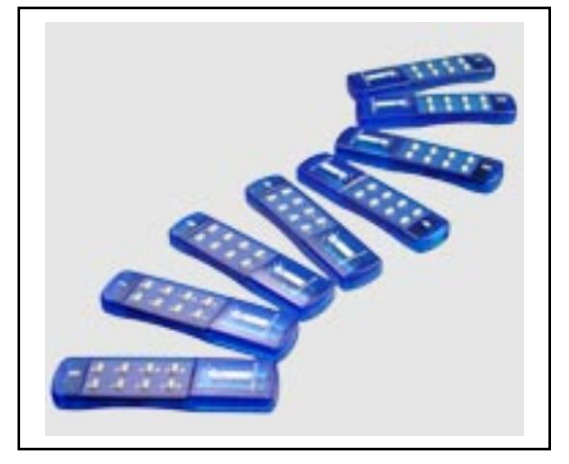
fifteen questions. Once completed, the electronic response software grades all quizzes (up to 256 of them) and allows immediate access to analysis of the responses. A multitude of reports are available, but the most useful at this point is the Response Report, (see left) which provides frequency distribution of responses along with an indication of correct answer. Upon review of this report, the points of weakness in students' preparations are immediately apparent. The discussion 
session then focuses on the weakest comprehension of topics. Instead of class discussions or lectures having a large component of topics that almost everyone was successful in assimilating, the topics needing explanation, reinforcement, or other emphasis are at the class' center.

Each week's assigned topic has an audio-visual presentation created in Apple ${ }^{\mathrm{TM}}$ Keynote ${ }^{\mathrm{TM}}$, which includes a visually attractive and "wow" producing format that can be navigated easily to the specific topics identified in the Discussion Quiz as targeted content. The presentation also includes video clips to illustrate concepts and is shown to the students for them to complete the thought process of applying the concept to the video example. This visual approach seems to open faster more effective comprehension among students. Current speculation is that this increased effectiveness is a result of the methods employing multiple learning techniques in a short period of time and focusing on a specific topic.

\section{TACT IMPLEMENTATION}

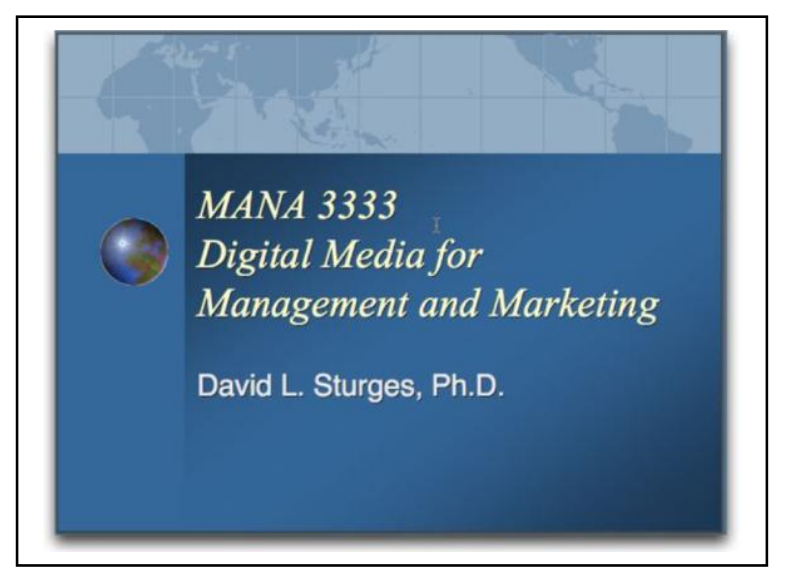

Implementation of the TACT Application System comprises two distinct sections. First is the classroom implementation of technological elements to create the opportunity to build a TACT Application System. For the most part, these installations in classrooms are driven by attempts to incorporate leading technologies at the time into easy to operate systems. The typical classroom installation includes a computer with Internet access, an LCD projector for large screen display, a stereo sound system, a VCR for videotape, a document camera, and, sometimes, a DVD player (perhaps in the computer). In addition, most installations include an option to connect portable computers into the system for presenters who have complex presentations on their computers that would be difficult to efficiently transport to the built-in computer in the classroom.

The cost of such installations can range widely depending on the quality of components, the extent of wiring processes, and warranty options. Installations can range from $\$ 12,000$ to $\$ 50,000$ for basic functionality.

Once the technology is installed, the focus shifts to faculty or others preparing presentation material for classes. The software to equip a TACT Application System includes a web server (includes serving html, php, and rstp for streaming video), web site creation and management software, graphics software, a website database, presentation software, non-linear video editing software, sound recording software, Macromedia Flash ${ }^{\mathrm{TM}}$ software, and access to online animation graphics. Hardware required includes a reasonably fast computer with Firewire ${ }^{\mathrm{TM}}$ connection, a 250 gigabyte hard disk (or bigger), a quality video camcorder, a microphone, and an audio mixer. In addition, server support software such as a discussion board and online survey creation software are important additions.

The cost of the TACT installation varies more widely than does the hardware installation. In the case of the software, a system using Microsoft ${ }^{\mathrm{TM}}$ products will be on the high side. A system using Apple ${ }^{\mathrm{TM} M A C}$ OSX or a UNIX operating system can take advantage of many open source program applications available at no charge or very little charge to license. Many of the commercial software applications have academic pricing that permits a school, faculty member, or student to acquire the commercial programs at greatly reduced prices. Apple ${ }^{\mathrm{TM}}$ and Macromedia ${ }^{\mathrm{TM}}$ are two such suppliers and the basis for the TACT System employed in our college. Total cost for a computer production area and all hardware and software as currently creating all components for the TACT Application System is approximately $\$ 6,000$.

Training is necessary for anyone to learn to use the TACT Application System software. Initial training is available from hardware and software suppliers, but the greatest part of the learning process results from the commitment, motivation, and time invested by an individual to become proficient in the production using the 
software. As more and more faculty at a specific university adopt the TACT approach, the cost is more reasonable to include technicians with the capability to guide faculty in TACT component development and deployment. In the case of our college, the capabilities had to be developed first to demonstrate the effectiveness and efficiency of the learning method and its production.

\section{CONCLUSION AND FUTURE RESEARCH}

Since this is the first semester of the TACT Application System test, no empirical data currently exists. Anecdotal statements from students would indicate strong positive support for the techniques and testing suggests comprehension of course material is more complete because of the application of critical-thinking exercises throughout the TACT System components.

Four sections of a course are offered this semester. Two are standard physical sections employing limited technological support to classes. Internet resources and quality in-class presentations are the limit. One section is completely online but includes almost all TACT components with slightly altered application from what is detailed here. The fourth section is called a Hybrid section and is the test bed for the TACT Application System.

At the close of this semester, the results of student competency acquisition and retention will be tested to determine if any differences result from the different techniques. The hypothesis is that students in the TACT group will achieve significantly greater comprehension of basic concepts than will students in the other teaching format classes. This hypothesis is based on the understanding that populations of students are comprised of people with different learning styles. More importantly the hypothesis relates to the TACT Application System fostering enhanced decision-making and critical-thinking skills to activate and navigate the course's content.

Results of the data analysis will be reported as soon as it is available.

\section{REFERENCES}

1. Banas, Edward J. \& Emory, Frances W. (1998). History and Issues of Distance Learning. Public Administration Quarterly. 22:3. pp 365-383.

2. Bowerman, Margaret (2005). Successful Strategies for Meeting the Needs of Diverse Learners. The Journal: Technological Horizons in Education. 32:10. pp 20-24. May 2005.

3. Goodhue, Dale (1995). Task-Technical Fit and Individual Performance. MIS Quarterly. June. pp 213-236.

4. Karahanna, Elena, Straub, Detmar, and Chervany, Norman (1999). Information Technology Adoption across Time: A Cross-Sectional Comparison of Pre-Adoption and Post-Adoption Beliefs. MIS Quarterly. 23:2. June. pp 184-213.

5. Lewis, Nancy and Orton, Peter. (2000). The five attributes of innovative e-learning. Training and Development. 54:6. pp 47-51.

6. Sturges, David. (2004). Robust Edutainment for On-Line Course Delivery. Journal of College Teaching \& Learning. (refereed). CIBER Research Institute 1:9 (September, 2004) pp.1-8. ISSN 1544-0389.

7. Van Gelder, Timothy (2001). How to improve critical-thinking using educational technology. ASCILITE. Melbourne, Australia.

8. Zielinski, Dave. (2000), Can you keep learners online?. Training. 37:3. pp 64-75. 


\section{NOTES}

